\title{
Do Affluent Countries Violate the Human Rights of the Global Poor?*
}

\begin{abstract}
In this article I consider Thomas Pogge's thesis that affluent countries are violating the human rights of the global poor by contributing support to the current global institutional order. My claim is that affluent countries are not violating the human rights of the global poor in the ways suggested by Pogge. I start by defining a set of conditions that ought to obtain in order to say that a human rights violation has taken place. Then I consider two possible interpretations of Pogge's thesis and argue that none of them fulfills the conditions required to speak of a human rights violation. On my view, as long as domestic states have the capacity to fulfill the human rights of their own people, poverty constitutes a domestic human rights violation even if the international institutional order somehow contributes to creating this state of affairs. Finally, I examine what transnational duties human rights entail and claim that affluent countries must contribute to the creation of an international order providing domestic states accurate background conditions for the promotion of human rights at the domestic level.
\end{abstract}

KEYWORDS: Human rights, poverty, background adjustment, responsibility, perfect duties, Thomas Pogge

\section{Introduction}

Global poverty constitutes the most critical problem of our time. Some three billion human beings, representing around half of the world's population, live below the poverty line and lack the minimum requirements to lead a decent human life. ${ }^{1}$ This means that they have no access to food, clean water, clothing, shelter and basic medical care. Some 18 million people, most of them children, die each year due to starvation and other poverty-related causes. Although this situation is deeply tragic, theorists disagree on what kinds of actions must be undertaken to remedy it. Thomas Pogge has recently made an important contribution to this debate by suggesting that global poverty constitutes a human rights violation on

\footnotetext{
* I would like to thank Miriam Ronzoni, Laura Valentini, Saladin Meckled-García, Osvaldo Guariglia, Pablo Gilabert and the editors of this journal for their useful comments on this paper as well as the National Agency for Science and Technology of Argentina (PICT 38-190) for its financial support.

1. For the purposes of this article a person can be considered poor when she lives with less than 2 US dollars per day and very poor when she lives with less than 1 US dollar per day.
} 
the part of affluent countries. ${ }^{2}$ On his view, affluent countries are violating the human rights of the global poor by supporting an international institutional order that makes their access to the objects of their basic needs avoidably insecure.

This article examines Pogge's thesis and aims to explain in what sense global poverty can, and in what sense it cannot, constitute a human rights violation on the part of affluent countries. My main claim is that affluent countries are not violating the human rights of the global poor in the way postulated by Pogge. In this vein, I will argue that as long as states possess effective sovereignty and are capable of delivering on the human rights of their people, poverty constitutes a domestic human rights violation rather than a transnational human rights violation, regardless of whether the international global order is fair or not. Poverty can only be regarded as a human rights violation on the part of affluent countries when states are too poor or too weak, through no fault of their own, to deliver on human rights. This conclusion provides a better understanding of how human rights can help the fight against global poverty.

I will also argue that there is no easy solution to global poverty in the sense that its eradication cannot be achieved by any simple measure, such as an international tax whose revenue would be distributed among poor people or poor nations. In addition to any measure of this kind, complex institutional and regulatory mechanisms will have to be built in order to stop international interaction from eroding state sovereignty, and exacerbating the power-imbalances already marking the international realm.

The article starts by defining a set of conditions that must obtain before it can be said that a human rights violation is taking place. These conditions are already implicit in the most familiar conceptions of human rights and can be accepted by Pogge and other cosmopolitan theorists. ${ }^{3}$ In this sense, the article will simply make explicit a set of conditions that most theorists, including many cosmopolitans, would accept upon due reflection. Once these conditions have been defined, I explain why affluent countries are not violating the human rights

\footnotetext{
2. See Thomas Pogge, 'An Egalitarian Law of Peoples', Philosophy and Public Affairs 23/3 (1994), 195-224; Thomas Pogge, 'The International Significance of Human Rights', The Journal of Ethics 4/1-2 (2000), 45-69; Thomas Pogge, World Poverty and Human Rights (Cambridge: Polity Press, 2002); Thomas Pogge, 'Recognized and Violated by International Law: The Human Rights of the Very Poor' (2008) available online at <http://www2.ohchr.org/english/issues/poverty/ expert/docs/Thomas_Pogge_new.pdf> ; Thomas Pogge, 'Severe Poverty as a Violation of Negative Duties', Ethics and International Affairs 19/1 (2005a), 55-81; Thomas Pogge, 'Real World Justice', The Journal of Ethics 9 (2005b), 29-53; Thomas Pogge, 'Human Rights and Human Responsibilities' in Andrew Kuper (ed.), Global Responsibilities (New York: Routledge, 2005c), 3-35; Thomas Pogge, 'Severe Poverty as a Human Rights Violation', in Thomas Pogge (ed.), Freedom from Poverty as a Human Right (Oxford: Oxford University Press, 2007), 11-53.

3. A notable exception is Elizabeth Ashford, 'The Duties Imposed by the Human Right to Basic Necessities' in Thomas Pogge (ed.), Freedom from Poverty as a Human Right (Oxford: Oxford University Press, 2007), 182-218; also see my discussion of Ashford's view in 'Global Poverty, Human Rights and Correlative Duties', Canadian Journal of Law and Jurisprudence 22/1 (2000), 79-92.
} 
of the global poor - at least not for the reasons invoked by Pogge. Finally, I examine what transnational duties the human right to subsistence entails and maintain that affluent countries must contribute to the creation of an international order providing every state with the background conditions required to honor the human rights of their people.

It is important to note that I do not intend to claim that poverty is not a human rights problem demanding immediate action. My sole claim is that as long as states have the capacity to adopt domestic policies neutralizing the effects of the international order, poverty constitutes a domestic human rights violation rather than a human rights violation on the part of affluent countries across borders.

\section{Three conditions for violating human rights}

Violating a human right constitutes a severe moral fault, but not every severe moral fault constitutes a human rights violation. Rather, the types of acts classifiable as human rights violations are a subgroup of the broader class of all the morally wrong acts and certain conditions must obtain in order for us to say that a human right has been violated. Let me outline these conditions.

First, an act, either an action or an omission, constitutes a human rights violation if there is an agent, $\mathrm{A}$, who has a valid claim to an object $\mathrm{X}$, which in virtue of the key interests it preserves can be regarded as the object of a human right. Naturally, we can have rights or claims to many objects which are not proper objects of a human right. We have, for example, a claim not to be robbed of the candies we have just bought, or a claim to have our gardens free from garbage. But none of these claims is a claim to the object of a human right, since, normally, neither having our candies stolen, nor having some garbage in our gardens affects any of our key interests. Unless this condition is accepted, there would be no relevant difference between human rights and other moral rights, and the concept of human rights would play no distinct role in our moral and political life.

Second, the mere fact that someone interferes with the satisfaction of a valid claim to on the part of A, or refuses to provide A with access to the object of this claim, is a necessary, though not a sufficient, condition to classify this act as a human rights violation. This can be illustrated with a simple example: While it may be acknowledged that human beings have a claim to life and to avoid premature death, this does not imply that B's interfering with A when A is stealing her money, which A needs to avoid starvation, or B's denial to pay for A's food, constitute a violation of A's human right to life on the part of B. Put differently, maintaining that $\mathrm{A}$ has a claim to $\mathrm{X}$ does not entail that $\mathrm{A}$ has a moral claim on everyone else 
to behave so as to ensure A's access to X. ${ }^{4}$ Speaking of a human rights violation thus requires demonstrating that $\mathrm{A}$ has a claim against some other clearly identifiable agent or agents to act in a certain way that has been disregarded. ${ }^{5}$ It is precisely because human rights entail claims against some other agents to behave in certain ways that they can lead to important political reforms. Otherwise it would be impossible to demand that others undertake actions to honor them and they would become nothing more than mere aspirations, or, what is worst, empty rhetoric. ${ }^{6}$

Now, conferring on an agent A a claim against some other agent B concerning $\mathrm{X}$, means assigning $\mathrm{B}$ a duty towards $\mathrm{A}$. An agent $\mathrm{B}$ would then violate A's human right to $X$ insofar as she infringes her duty towards $A$ concerning $X$. This raises the question of when a duty correlative to A's claim to X can be fairly attributed to B. Such a duty would not be morally justified unless B had the capacity successfully to discharge her duty towards A, either because she possesses the means required for this or because she can reasonably acquire those means. For example, I cannot have a duty to save someone who is drowning if, for some reason, I am unable to swim (and swimming was necessary for a successful rescue). But I would have such a duty if I could save the drowning person by using a boat that I could learn to operate by simply reading the instructions. Naturally, B cannot be assigned any duty towards $\mathrm{A}$ if fulfilling this duty implies disregarding other duties that have priority over her duty towards A. ${ }^{7}$ For instance, I cannot have a duty to feed some poor children in Africa if this implies starving my own children. Likewise, no state can be asked to improve the security of its citizens if this can only be done by torturing people who may have loose connections with international terrorism. The conditions for assigning duties can be expressed through this formula:

Agency Condition: An agent B can be assigned a duty D concerning another agent's A claim to an object X, only if B can successfully discharge this duty. Whenever B's fulfillment of D would require the possession of means - material resources, money, knowledge, abilities, influence, authority, etc.- that B lacks or cannot reasonably acquire, or would force B to neglect a more stringent duty, neither can $\mathrm{D}$ be fairly imposed on $\mathrm{B}$, nor can failure to meet the demands of $\mathrm{D}$ be regarded as a violation of A's right to $\mathrm{X}$ on the part of $\mathrm{B}$.

4. See Robert Nozick, Anarchy, State and Utopia, (Basic Books, 1974), pp. 191-192. See also Thomas Pogge (2005a), p. 68; and Henry Shue, 'Mediating Duties', Ethics 98/4 (1988), 687-704, p. 689. While these conditions may not be accepted by a radical utilitarian, radical forms of utilitarianism seem to face so many problems - which have already been discussed in the contemporary debate - that I do not need to address their potential objections here.

5. Or as Onora O'Neill puts it; 'Any right must be matched by some corresponding obligation, which is so assigned to others that right-holders can in principle claim or waive the right.' Onora O’Neill, Towards Justice and Virtue (Cambridge: Cambridge University Press, 1996), p. 129.

6. Onora O’Neill, 'The Dark Side of Human Rights', International Affairs 81/2 (2005), 427-439, p. 427.

7. James Nickel, 'How Human Rights Generate Duties to Protect and Provide', Human Rights Quarterly 15/1 (1993), 7786, p. 86; and Thomas Scanlon What We Owe to Each Other (Cambridge Ma.: Harvard University Press, 1998), p. 286. 
Third, in order to maintain that B is violating A's human right to X, B's duty towards A concerning X must be a perfect, as opposed to an imperfect, duty. Whereas perfect duties mandate an act which must be performed in a nondiscretionary way, imperfect duties refer to acts that the agent may choose how, when, and how often to discharge. ${ }^{8}$ A classical example of the latter kind of obligations is the duty of beneficence. In this respect, my having a general duty of beneficence does not compel me to help this particular beggar in this particular situation by giving her exactly what she needs: I can always choose to help some other deprived person or to carry out other kind of activities in favor of the worstoff at home or abroad. Therefore, in case the beggar starves, it cannot be claimed that it was my fault. ${ }^{9}$ Due precisely to this discretionary nature, imperfect duties are not owed to specifiable individuals and consequently cannot be the basis for claims against other clearly identifiable agents. ${ }^{10}$ This is the reason why speaking of a human rights violation as opposed to a mere human rights deficit necessarily requires the violation of a perfect duty.

This conception of human rights violations can be summed up in the following principle of responsibility for human rights violations: B violates A's human right to $\mathrm{X}$ if and only if (i) A has a valid claim to $\mathrm{X}$, where $\mathrm{X}$ is a proper object of a human right; (ii) B neglects a perfect duty D regarding A's access to X; and (iii) D can be fairly imposed on B in view of the Agency Condition.

If affluent countries violate the human rights of the global poor this would constitute a collective human rights violation, that is, a human rights violation produced by the actions or activities of various agents. Collective human rights violations can be at least of two kinds. They can be violations perpetrated by a collective agent, such as an army, a transnational corporation, or a political community. In these kind of cases, before it can be said that those belonging to the collective agent violated human rights through their participation in this agent, it must be shown that the collective agent did violate human rights. And this means that it must be shown that this collective agent violated some perfect duty, which, either alone or in combination with the violation of other perfect duties on the part of other agents, led to a human rights deficit. In this vein, before we can say that Nike, for example, violates human rights, it must be shown that it is violating some perfect duty, such as the duty not to exploit workers or the duty to respect certain labor standards. The human rights of the workers may be violated as a result of the activities of Nike combined with the activities of other

8. O’Neill (1996), pp. 147 and 152; and Shue (1988), p. 688.

9. Shue (1988), p. 703.

10. Shue (1988); O’Neill (1996), pp. 151-152; Allan Buchanan,, Justice, Legitimacy and Self-Determination (New York: Oxford University Press, 2004), p. 195; and Maurice Cranston, What Are Human Rights? (New York: Tapingler Publishing, 1973), p. 68. 
agents (e.g., the lack of an accurate legislation in the country, the actions of other corporations, the influence of international organisms and so forth), but Nike would not be involved in that violation unless it were violating some perfect duty.

Alternatively, collective human rights violations can be violations perpetrated not by a collective agent but by several agents performing different actions at the same time or consecutively. Suppose that several factories release toxic waste into a river. Although none of these toxic substances taken alone can cause any important harm, when these toxic substances add up they poison some children living in a nearby village. ${ }^{11}$ The factories were not acting together as part of a plan, but simply trying to get rid of the waste in a cheap way. However, they could foresee that their activities could result in the poisoning of the villagers. In these cases, the human rights violation could be attributed, in principle, to all the factories, their directors and some of their workers as long as they violated some perfect duty applying to them - of course, corrupt or negligent public officials could also be added to the list. Consequently, in this sort of violation, infringements of perfect duties, such as the duty not to carry out activities that will predictably interfere with the access of other people to the objects of their human rights, are involved as well.

There are two potential objections against this conception of human rights violations that must be tackled.

First, it could be said that this conception of human rights violations is oversimplified. This objection maintains that in the real word human rights violations are the result of a synergy of actions and activities carried out by a myriad of agents which may be hard to identify. On this view, when the human rights of political dissenters are violated in a certain country, this is not simply the product of a decision by an official agent, but also the product of the main political institutions being organized in a certain way, the failure of the citizenry to reorganize these institutions, and the indifference of the international community. I have no intention to deny this. On the contrary, I accept that human rights violations may be brought about by the actions of several agents and involve a dense network of activities and connections. My sole claim is that when we speak of human rights violations, at least at a certain stage of the process some perfect duty must be violated by some clearly discernible agent or agents. Depending on the conception of human rights we have in mind, this can be the duty of the government to implement or refrain from implementing certain public policies, the perfect duty of a political community to organize or refrain from organizing its main political institutions in a certain way, the duty of the citizens to work to

11. Pogge (2007), p. 45 . 
achieve new forms of political organization, or all these duties at the same time. But, although the nature of the perfect duty being violated may vary according to our conception of human rights, it would be impossible to speak of a human rights violation if no perfect duty is violated. Otherwise, who would be the violator? If no one has violated a perfect duty regarding the starving beggar, who would be violating her human right to necessary food? Would it be those who passed by him and did not give him a coin? Would it be those not making donations to charities within the country? Would it be those not undertaking some sort of political action in favor of global justice around the world? Would it be all those supporting market economies all over the world? My conception does not exclude that we attribute this human rights violation to the public officers who failed to aid him, to the members of parliament who were reluctant to support the adequate laws, or to constituencies involved in illegal activities to advance their interests at the expense of social justice. In this respect, my conception does not maintain that we can only speak of a human rights violation when this violation can be attributed to the violation of only one perfect duty on the part of just one agent. In fact, a human rights violation may correlate with the violation of several perfect duties on the part of several agents, which may combine in extremely complex ways. My conception simply excludes that we speak of human rights violations when no perfect duty was violated by any agent at all.

It is also important to explain that my conception of human rights violations is not incompatible with complex theoretical or moral explanations of human rights violations or with maintaining that many actors not directly connected to the violation bear some sort of responsibility for this violation. Famines in Burundi can be explained by making reference to the political decisions of the government of Burundi, but also by making reference to decisions taken by the government of the US regarding the subsidies protecting cotton producers, to the activities of unscrupulous market agents, or to the attitude of millions of selfish people who purchase certain products or support certain laws no matter what consequences this may have for remote strangers. Likewise, even if an agent has no direct connection with a human rights violation, it could be said that he bears some kind of responsibility, at least as long as this individual does not devote any efforts to work towards stopping human rights violations.

Second, it could be said that, although this conception of human rights violations is independently plausible, it would not be accepted by Pogge. Consequently, his original argument regarding global poverty and affluent countries would remain untouched. But I think this objection is mistaken, since there are in fact reasons to think that Pogge would not reject my conception of human rights violations. Indeed, Pogge would accept the first condition since he thinks that human rights 
entail claims to the satisfaction of certain interests which are vital for human beings. He would also accept that human rights involve claims against other agents since he thinks that human rights impose duties on others. Finally, at least when it comes to global poverty, Pogge would not dispute the idea that human rights violations involve the violation of perfect duties since he believes that the affluent countries have no discretion regarding their negative duty not to impose unfair institutions on others. The three conditions exposed above are then implicit in Pogge's claim against affluent countries and can therefore be fairly used to assess his thesis.

\section{In what sense affluent countries are not violating the human rights of the global poor?}

Pogge claims that the affluent countries are violating the human rights of the world's poor and are actively participating in a collective crime of enormous proportions. The reason for this is that they contribute to upholding an institutional global order that gives rise to an avoidable and foreseeable human rights deficit. ${ }^{12}$ By doing this, affluent countries violate a duty not to contribute to the imposition of an institutional scheme that foreseeably makes the access of the very poor to the objects of their basic needs avoidably insecure. ${ }^{13}$ For Pogge, this is a negative duty, as long as it merely demands affluent nations refrain from acting in certain ways rather than to perform positive actions in favor of the poor. And it is also a perfect duty, since affluent countries would have no discretion concerning its fulfillment in the same way we do not have discretion to decide whether to unduly inflict some harm on another person or to break a promise. ${ }^{14}$ In this respect, Pogge compares affluent countries with the Americans that cooperated in imposing a national institutional order that enforced slavery and with the German citizens that facilitated the human rights violations committed by the Nazi regime through their support of it. ${ }^{15}$

Pogge's accusation against the affluent countries is that they violate the human rights of the global poor as long as the global institutional order they sustain

\footnotetext{
12. Pogge writes: 'The continuing imposition of this global order, essentially unmodified, constitutes a massive violation of the human right to basic necessities -a violation for which the governments and electorates of the more powerful countries bear primary responsibility.' Pogge (2008), p.20, see also Pogge (2002) p. 201; Pogge (2005), pp. 33 and 37; and Pogge (2005a), p. 21.

13. Pogge (2008) p. 21. Pogge's formulation is, actually, more complex. He blames affluent countries for upholding a global institutional order that renders the access of the world's poor to the objects of their basic needs avoidably insecure, without making compensating protection and reform efforts for its victims. However, this positive duty to compensate the victims of global poverty by means of protection and reform efforts constitutes what Pogge calls a 'generative duty'. This means that affluent countries will only be burdened by such a duty in case they are violating a previous negative perfect duty they had towards the global poor. So, the issue of whether they are violating their duty not to support the current institutional order can be considered separately. Only if they do have such a duty, they may then have a duty to undertake positive compensating actions.

14. Pogge (2005a), p. 68.

15. Pogge (2008), p. 3; and Pogge (2005a), p. 71.
} 
violates the human rights of these people. It is undeniable that affluent countries do have perfect duties not to take part in, or support, an institutional order or any other institutions that violate human rights. Consequently, the question is whether the global institutional order is actually violating any perfect duties regarding the human rights of the global poor. Otherwise, as Pogge himself concedes, those participating in it would be released of any charge of violating human rights. ${ }^{16}$

What we need to know, then, is what perfect duty regarding the global poor may the global institutional order be violating. There are two alternative ways of interpreting Pogge's demands on the global institutional order. On the first interpretation, the global institutional order would be violating a perfect duty not to be suboptimal in terms of poverty eradication. On the second interpretation, instead, the global institutional order would be simply violating a perfect duty not to impose asymmetrical rules on its participants, including rules for international trade, intellectual property, finance and borrowing. I will deal with these interpretations in turn.

\section{Interpretation 1: distributive patterns and the agency condition}

In some texts, Pogge suggests that he would denounce any global institutional order that is suboptimal in terms of poverty eradication as human rights violating. ${ }^{17}$ Consider the following passage:

Evidently, an institutional order can be minimally fair in the sense of treating all its participants equally, and nonetheless foreseeably reproduce avoidable human rights deficits. That I would consider such an order unjust is clear beyond any reasonable doubt. ${ }^{18}$

In this vein, he affirms that positive measures such as demanding 'higher tax payments from the more affluent, or permitting poor but not rich countries to impose currency controls against speculative inflows', are mandated whenever these measures 'are needed to avoid human rights deficits. ${ }^{19}$ It is possible to find support for this interpretation in Pogge's 'institutional understanding of human rights' and in his idea of a 'minimal standard of social justice', which constitute the very core of his view. The institutional understanding states that postulating a human right to X implies that any coercive social institutions should be organized so that all human beings affected by them should have secure access to $\mathrm{X} .{ }^{20}$ In turn, the minimal standard of social justice asserts that 'any institutional order

16. '[O]ne can question whether this order [the global institutional order] is human rights violating. If it is not, then participation in its imposition cannot constitute a human rights violation.' Pogge (2005b), p. 45.

17. Pogge (2005b), p. 42.

18. Pogge (2005a), p. 60.

19. Pogge (2005a), p. 62. 
imposed on human beings must be designed so that human rights are fulfilled under it insofar as this is reasonably possible'. ${ }^{21}$ As a result of these conceptual moves, any relevant difference between acting and omitting, causing and letting happen, and harming and refusing to aid, is definitely erased, and any failure in adopting every feasible positive measure to prevent poverty will represent a violation of a perfect negative duty not to harm. This means that any institutional order which is suboptimal in poverty avoidance or eradication could be engaged in an active human rights violation. ${ }^{22}$

To see the institutional consequences of this interpretation, consider four alternative institutional orders:

O1 imposes asymmetrical rules on its participants.

$\mathrm{O} 2$ is a fully symmetrical order which enforces no special measures aimed at alleviating the situation of the worst-off.

$\mathrm{O}_{3}$ is a fully symmetrical institutional order that mandates some measures aimed at avoiding poverty, though not all possible measures in this respect.

$\mathrm{O}_{4}$ is an institutional order including every feasible measure to maintain a pattern of distribution among its participants that ensures that all of them will have secure access to the objects of their basic needs, except under exceptional circumstances such as a natural catastrophe.

On this interpretation, $\mathrm{O}_{1}, \mathrm{O}_{2}$ and $\mathrm{O}_{3}$ are human rights violating regimes since the insecurity in the access to the objects of the basic needs of the very poor registered under them would be preventable by the adoption of further measures and, hence, is institutionally produced. Only $\mathrm{O}_{4}$ would avoid the charge of being human rights violating, for only under it no human rights deficit could be traced back to institutional variables. ${ }^{23}$ Thus the perfect duty towards the world's poor that the global institutional order is infringing would be the duty to secure a distributive outcome in which nobody avoidably falls below a minimum threshold of access to essential goods due to institutional factors.

20. Pogge (2002), p. 46.

21. 'The institutional approach involves a conception of distributive justice that differs sharply from the one Walzer supports and Nozick attacks...On the particular view I defend, for example, we should aim for an economic order under which each participant would be able to meet her basic social and economic needs. A conception of distributive justice understood in this way, as providing a standard for the moral assessment of alternative feasible schemes of economic institutions, is prior to both production and distribution occurring under such schemes and therefore involves neither the idea of an already existing pool of stuff to be doled out nor the idea of already owned resources to be re-distributed.' Pogge (2002), p. 176.

22. Alan Patten, 'Should We Stop Thinking about Poverty in Terms of Helping the Poor?', Ethics and International Affairs 19/1 (2006), 19-27, p. 27; Rowan Cruft, 'Human Rights and Positive Duties', Ethics and International Affairs 19/1 (2006), 29-37, p. 31; and Pablo Gilabert, 'The Duty to Eradicate Global Poverty: Positive or Negative?', Ethical Theory and Moral Practice 7/5 (2004), 537-550, pp. 541-542.

23. Pogge (2005a), pp. 55, 60 and 62; Pogge (2002), p. 199; and Patten (2006) p. 27. 
The problem with this interpretation is that no such a duty can be fairly imposed on the global institutional order in view of the Agency Condition. The main reason for this is that no particular distributive outcome can be guaranteed simply by the adoption of some partial global measures. However positive such measures may be in the short term, they are unlikely to satisfy Pogge's standard of social justice over time. Imagine, for instance, that the international trade system is redesigned so as to offer the poorest countries wide facilities to sell their agricultural products within the markets of the developed ones. It is doubtful whether this would allow them to provide the whole of their populations with secure access to the objects of their basic needs. But even if this were so, this situation may be altered in the future due to possible falls in the international prices of their exports, to sudden changes in market preferences and behaviors, to technological innovations, or to commercial competition. ${ }^{24}$ Or imagine, alternatively, that the World Bank is required to provide developing states with cheap loans so that they can engage in a state-sponsored build up of industries capable of producing low-tech consumer products. Here, again, it should be noticed that an astonishing success in achieving economic growth on the part of some countries may have dramatic repercussions on some other economies by reducing their export markets and prices. ${ }^{25}$ To be sure, like the behavior of individuals, any of these changes can have unintended and even unforeseeable effects.

Nor will redistribution of money through, say, an international tax, such as the Global Resources Dividend proposed by Pogge, manage to ensure that everybody will have secure access to the objects of their basic needs across the globe. Not only can important transfers of financial resources into an economy cause inflation and reduce the purchasing power of the very poor, but they can also be detrimental for local production, employment, and ongoing industrialization processes, by fostering a massive importation of foreign goods. Even if this type of international tax succeeded in alleviating the situation of the least advantaged, it may distort the international economy and lead to the emergence of new poor people in already developed countries or among the middle classes of developing ones.

These reflections converge in suggesting that the kind of global distributive pattern that this interpretation of Pogge's thesis demands will not be achieved and maintained without a global regulatory authority constantly adjusting for

24. Saladin Meckled-Garcia, 'On the Very Idea of Cosmopolitan Justice', The Journal of Political Philosophy 16/3 (2008), 245-271. See also, Allen Buchanan 'Rawls' Law of Peoples: Rules for a Vanished Westphalian World', Ethics 110/4 (2000), 697-721, p. 701.

25. Pogge (2008), p. 14. At the same time, if the population of the developing states were able to exert a substantial market demand on goods and commodities, the resulting levy in their international price may end by jeopardizing the access of even more people to them, increasing, thereby, the number of deprived people worldwide. Notice that this danger is much more acute in the case of scarce strategic resources such as petroleum, as long as any substantive rise in its price may deeply harm hundreds of domestic economies all over the world. See Meckled-Garcia (2008). 
distributive fairness. In practical terms, this requires a continuous modification of the rules guiding the working of the whole network of international institutions and private arrangements, so that any impact eroding justice is neutralized and the overall distribution of the social system remains just irrespective of how things may turn out. ${ }^{26}$ Otherwise, the myriad of decisions and actions undertaken by individual actors, together with natural and social accidents, may unavoidably lead to the impoverishment of some particular countries.

This sort of continuous adjustment calls for an authoritative body with the moral and political powers to make binding pronouncements about what justice demands and to allocate rights and duties. ${ }^{27}$ In the domestic case, the imperatives of social justice fall on the basic structure, that is, on the main social and political institutions of a society. Therefore, the relevant question for our debate is whether a similar agent exists in the international realm. In the absence of a global agent with basic structure-like features, no agent could be fairly imposed the duty of ensuring a distribution under which every single person has secure access to the objects of their basic needs for it will have no agency to do so. In turn, if no perfect duty is violated, then no human rights violation is taking place.

It is sometimes thought that an international equivalent to a domestic basic structure does exist. This thesis can be grounded on the fact that the states affect the life prospects of individuals beyond borders in ways that may be positive or negative, and in the existence of a whole frame of institutions and arrangements regulating international interactions, which include the several regional and international economic agreements, especially the World Trade Organization, an international financial regime, a system of private property rights, as well as the myriad of informal practices of economic policy coordination. ${ }^{28}$

No doubt, it is true that the increasing interdependence registered nowadays in the global realm is so deep and complex that the inhabitants of any single state can be acutely affected by the actions and decisions undertaken by other states and

26. John Rawls, A Theory of Justice, revised edition (Cambridge, Mass.: Harvard University Press, 1999), p. 243. See also Samuel Freeman, 'The Law of Peoples, Social Cooperation, Human Rights and Distributive Justice', Social Philosophy \& Policy Foundation 23/ 1 (2006), 29-68, p. 61.

27. See Thomas Christiano, 'Secession, Democracy and Distributive Justice', Arizona Law Review 37 (1995), 65-72, p. 65; Meckled-Garcia (2008), p. 4; Allen Buchanan, Justice, Legitimacy and Self-Determination (Oxford: Oxford University Press, 2004), p. 219; and Thomas Nagel, 'The Problem of Global Justice', Philosophy \& Public Affairs 33/2 (2005), 113 47, pp. 116 and 131.

28. In this vein, Buchanan says: 'The extent to which various global financial regimes, governance structures, economic agreements, and private property rights systems affect the distribution of benefits and burdens among peoples and individuals is certainly open to dispute. What is not open to dispute is that these institutions do have distributional effects, and that means that there is no denying that there is a global basic structure. But if there is a global basic structure, then a moral theory of international law cannot afford to ignore its existence.' Buchanan (2000), p. 710. See also, Buchanan (2004), pp. 209 and 213; Charles Beitz, Political Theory and International Relations (Princeton: Princeton University Press, 1999), p. 149; Pogge (1994), p. 220; Brian Barry, The Liberal Theories of Justice (Oxford: Oxford University Press, 1973), pp. 128-133; and Shuen (1988), p. 694. 
transnational actors. And it is also true that there is a more or less dense network of international institutions that, to some extent, determine the life prospects of individuals beyond borders. But this is, nevertheless, not sufficient to prove that a global basic structure or any other agent cable of preserving certain distributive patterns over time exists.

Although the idea of a basic structure is in part defined by reference to its influence over people's life prospects, there are many social arrangements and institutions - families, universities, banks, markets - which do have the same kind of impact and are regarded neither as basic-structure-like agents, nor as proper agents of social justice. As to this, Rawls explicitly distinguishes between a set of rules or institutions guiding a practice, on the one hand, and the basic structure of society, on the other. ${ }^{29}$ Apart from having enduring effects on people's future hopes and possibilities, I think that a basic structure must possess at least two further characteristics, namely:

(a) It ought to constitute a unified or central agent encompassing all the major social institutions and fitting them together into one and the same scheme

(b) It must be able to assign fundamental rights and duties that determine the division of advantages arising from social cooperation and to secure compliance with them. ${ }^{30}$

These are the features which allow the basic structure to preserve certain distributive patterns by coordinating and rearranging the functioning of the multiple laws, regulations, and norms that underlie an economy. Thus, any entity lacking the powers to determine the working of the social system of institutions as a whole through the imposition of rights and duties will not be a basic structure at all. ${ }^{31}$

Although the so-called international institutional order is supposed to impose some restrictions both on international practices and on the domestic behavior of states, it is not a unified political agent capable of regulating the activities

29. Rawls (1999), p. 50.

30. It might be objected that the basic structure constitutes only the passive set of institutions and relations to which the principles of justice ought to be applied, but does not include the agent applying those principles itself - which in the domestic case is the state. I disagree with this understanding of Rawls' concept of the basic structure. As far as I can see, the following paragraphs make it clear that the idea of the basic structure already includes an active agent of justice: 'The basic structure is understood as the way in which the major social institutions fit together into one system, and how they assign fundamental rights and duties and shape the division of advantages that arises through social cooperation', and '[n] ow by assumption the basic structure is the all-inclusive social system that determines background justice.' Rawls (1996), pp. 258, 272. See also, Rawls (1999), p. 6. Nevertheless, even if my interpretation of the idea of the basic structure is misleading, my general argument against Pogge will not be damaged, for no agent capable of applying principles of global distributive justice exists at the international level.

31. Christiano puts the point as follows: 'The chief insight here is that the establishment of justice requires coordination among the many different actors and institutions on a single set of laws coupled with juridical and executive institutions to back them up.' Christiano (1995), p. 6o. See also, Freeman (2006), p. 39, 40-41; Meckled-Garcia (2008), pp. 8 - 9; and Michael Blake, 'Distributive Justice, State Coercion and Autonomy', Philosophy \& Public Affairs 30/3 (2002), 257-296, pp. 265 and 288. 
of international institutions, countries and transnational actors as a whole. Rather than a single global institutional order, the international arena seems to be composed of several decentralized arrangements and bodies originated in successive agreements between states, each of them having their own specific aims. In the same way, the global institutional order cannot assign rights and duties in an authoritative way. This is so because its political powers rely on the compliance of the many independent states, which voluntarily accept obligations by ratifying international pacts and treaties. ${ }^{32}$ Therefore, no agent comparable to a domestic basic structure exists in the global sphere. ${ }^{33}$

In terms of this paper, all this implies is that the current scheme of international institutions has no agency to maintain the kind of adjustment required to preserve the appropriate distributive pattern among persons across borders. Therefore, on interpretation 1 the global institutional order cannot be blamed for violating the human rights of the world's poor, since it has neglected no perfect duty burdening it.

It can be objected, however, that although no global basic structure exists this is not relevant for the debate I am facing. The relevant question, instead, would be whether in view of already existing sorts of relations and interactions we should not create some sort of global basic structure. ${ }^{34}$ This objection could be understood as meaning that justice demands the creation of new institutions or as meaning that human rights demand the creation of new institutions. I think that on neither of these readings this touches my argument. If this objection is taken to be about justice, it does not touch my argument since in this article I am not concerned with justice, but simply with human rights. If the objection is taken to be about human rights, then I may agree with part of it as well. In fact, I do accept the view that human rights may require the creation of new institutions we may have perfect duties to bring about. However, as I will explain in next section, I do not think that human rights should lead us to the creation of a global basic structure comparable with the domestic one. ${ }^{35}$

\footnotetext{
32. To put it in Samuel Freeman's words, 'global political power remains supervenient upon the political power of independent peoples.' Freeman (2006), p. 40

33. Rawls himself seems to suggest this in his 'The Law of Peoples' in S. Shute and S. Hurley (eds.), On Human Rights: The Oxford Amnesty Lectures 1993 (New York: Basic Books, 1993), pp. 220-221, footnote 2.

34. This view has been recently put forward by Miriam Ronzoni, 'The Global Order: A Case of Background Injustice? A Practice-Dependent Account', Philosophy \& Public Affairs 37/3 (2009), 229-256, pp. 242-249. To put this objection in the terms of Arash Abizadeh, it could be said that a basic structure is not an existence condition for the demands of justice. Quite the contrary, the demands of justice may perfectly require the realization of a basic structure as necessary conditions of it. See Arash Abizadeh, 'Cooperation, Pervasive Impact, and Coercion: On the Scope (not Site) of Distributive Justice', Philosophy \& Public Affairs 35/4 (2007), 318 - 358.
} 


\section{Interpretation 2: unfair background conditions and the system of states}

On the second interpretation, the global institutional order has no duty to eradicate global poverty but simply to adopt fair international rules that could reduce global poverty. Therefore, affluent countries would be violating the human rights of the global poor insofar as they go on sustaining the current institutional arrangements when less burdensome conditions for the global poor are available. If, after adopting a fair international order in the lines of O2, global poverty persists, then this would constitute a purely domestic human rights violation and the affluent countries would not be to blame for this.

There is no doubt that the current global institutional order is terribly inefficient in terms of poverty eradication. It is also clear that it actively contributes to the maintenance and generation of poverty all around the globe by imposing unfair institutions, rules and relations. Paradigmatic examples of this are the successive international trade agreements adopted during the last decades. These agreements have forced the poorest countries to open their markets to the products coming from the developed economies, but allowed the rich nations to protect their producers, mainly those producing commodities, through the imposition of subsidies and tariff barriers. This has caused the bankruptcy of millions of small farmers in the poorest countries, redirected several billion dollars from these economies to those of the richest nations, and seriously affected the capacity of the poor states to deliver on the human rights of their citizens. Needless to say, the fact that these rules have been endorsed by the governments of the poor countries in several international meetings is no argument in favor of them, since this endorsement has been conditioned by the superior bargaining power of the rich states.

In view of these and other similar considerations, it could be concluded that affluent countries are violating the human rights of the global poor. More precisely, they would be violating the human rights of those who stay or become poor, or extremely poor, by infringing their perfect duty not to impose or not to contribute to the imposition of unfair or exploitative conditions on other states.

35. In this vein Ronzoni says: 'If we subscribe to this picture, what we need to ask is the following: in the current global scenario, are states capable of maintaining effective sovereignty in their interaction without the support of supranational regulatory institutions? This question shows how our ultimate concern is for what Rawls calls "the essentials of political autonomy", or, to put in other words, for the interdependence between global and social justice. For, in a situation of sufficiently strong interdependence, a fair international background might be necessary to allow all sovereign states to have a fair chance to implement policies they see fit. Hence, the global order might be (background) unjust in that it might generate problems of background justice under the form of threats to effective sovereignty.' Ronzoni (2009), p. 249. I completely agree with the conceptual point made in this passage. The main disagreement between this view and the one I am defending is that whereas Ronzoni seems to think that a proxy to some sort of global basic structure may be required to achieve the kind of background adjustment necessary to allow all states to have the capacity to exercise real or effective sovereignty, I think that we need much less than this. But this seems to be more an empirical disagreement rather than a conceptual or a political one. 
However, the mere fact that a certain agent does something, even something unfair or morally wrong, which causes, or contributes to causing, a human rights deficit in a preventable and foreseeable way, is not enough to blame this agent for a human rights violation. Imagine that I run a small shop selling fertilizers to farmers living in the area. You are one of my customers and you decide not to pay the fertilizers I sold you last week, knowing that this may cause me important financial problems. In order to deal with these financial problems, I decide to stop feeding my children so that I can continue to enjoy a decent lifestyle without having to work extra hours. Although there is no doubt that you have behaved in an immoral, illegal way, it would be problematic to jump to the conclusion that you are a human rights violator, or that you violated the human rights of the children. The reason for this is that I could have and should have prevented my children from starving by dealing with the financial problems in a different way (for example, by working extra hours, asking for a loan, etc.) The fact that you behave in an incorrect way does not entail that you bear (full) responsibility for whatever I do as a result of that. While you have violated my justice-based right to be paid for the fertilizer, I am the one who has violated my children's rights.

As the preceding example shows, we need not bear moral responsibility for all the states of affairs that we contribute to causing. Whether we bear moral responsibility for a certain state of affairs depends on considerations regarding responsibility. The reason why I am responsible for my children starving is that I had duties to undertake or not to undertake certain actions towards them. Likewise, whether a wrongful action constitutes a human rights violation or not depends, among other things, on considerations regarding responsibility for human rights. In this respect, we actually live in a system of states, where each state or organized political community is responsible for advancing the life prospects of their people and for achieving domestic justice, which certainly includes promoting human rights. This division of labor is not arbitrary. On the contrary, it seems that this system is the best, if not the only, way of making the human rights of everyone safe in a world where the remote effects of our actions may be unpredictable. This is because, as we have already seen, human rights require that certain distributive patterns are preserved over time so that the basic needs of the people are met. And only states seem to have the capacities and powers to make the necessary adjustments to preserve such distributive patterns from the cumulative effects of private actions and transactions.

Of course, the system of states is compatible with claiming that states also have duties regarding the human rights of people living beyond their borders. This includes duties to make any just contributions required by any fair international institutions, meaning by this institutions belonging to a framework of international 
institutions that ensure the background conditions that allow and, if necessary, force states or political communities to fulfill their human rights obligations. These duties also include an obligation not to impose unfair agreements, that is agreements that undermine the capacity of domestic states to honor the human rights of their people.

It can now be explained why affluent countries are not violating the human rights of the global poor under interpretation 2 either. Even when the global institutional order harms the economies of the poor countries and diminishes their capacity to deliver on the human rights of their citizens, poor countries could achieve this goal by adopting the necessary domestic policies, such as reducing their expenses on non-human rights-related activities, adopting redistributive policies, or, in hard times, asking for external loans. Although, as Pogge says, the imposition of unfair international institutions contributes to the human rights violations that take place all around the world, this does not lead to those violations in a necessary or fatal way. Rather, in the system of states, it is the action or inaction of domestic states that, given certain background conditions, violates human rights. Claiming that by imposing and upholding the current unfair institutional order the rich countries are violating the human rights of the global poor, would be the same as claiming that you starved my children when you decided not to pay for the fertilizers you purchased.

This is not to say that the decisions of domestic political communities are always the whole story about a human rights violation. In general, many other factors contribute to this violation and should also be taken into account. These factors may perfectly include the activities of international organizations, affluent countries, domestic elites, financial markets, and individuals all around the globe. But being part of the explanation of a human rights violation and even bearing some sort of responsibility for it is not the same as violating a human right. When I decide to starve my children in order to deal with my financial problems, my actions are hardly the only relevant explanatory or normatively relevant element. Your decision not to pay me is also part of the picture as well as an economic and political order where people like me are not protected against people like you. It is impossible not to look at these factors and not to care about them if we really care about human rights. But accepting this does not mean that you or the capitalist economy killed my children.

Now this is not intended to deny that affluent countries may be violating the human rights of some poor people in some extremely poor countries. This may be the case in certain countries in Africa or the Caribbean that constitute what Rawls has termed 'burdened societies', that is, societies so poor that they are not 
well-ordered and whose states lack effective sovereignty. ${ }^{36}$ But this does not seem to be the case in the north of Africa, China, India, Indonesia, South America, South Africa, and the oil producing countries in Asia and Africa. For example, by analyzing some historical cases, Amartya Sen has argued that famines and extreme poverty are not mainly due to lack of resources but rather to the lack of accurate public policies on the part of domestic governments, including policies regarding population control and gender equality. ${ }^{37}$ In 2005 , almost $18 \%$ of the population in Latin America and the Caribbean was poor. Although all the countries in the region where under the same global order and none of them is a developed country, the poverty rate in Costa Rica was only $2.3 \%$ against $11.6 \%$ in Colombia and $9.3 \%$ in El Salvador. ${ }^{38}$ This seems to suggest that in many cases domestic states could prevent poverty at home by adopting accurate public policies even if the international order is unfavorable to them. Therefore, whereas the affluent countries may be violating the human rights of some poor people, global poverty does not constitute a human rights violation by affluent countries in the sense implied by Pogge.

It could be objected that this way of conceiving of the distribution of responsibility for human rights is extremely simple and does not take into account the complexities of the real world. The reason for this is that in practice states do not always have the capacity to promote the human rights of their people. In fact, they can find big resistance on the part of powerful groups when they try to make important reforms. Thus full responsibility for the resulting human rights violation cannot be attributed to the affected states, and should instead be distributed among several agents, such as constituencies, companies, or financial powers who oppose human rights advancing measures simply because they do not favor their interests, or who, once these measures are adopted, pre-empt them or deprive them of any efficacy.

It is true that the world is becoming more and more complex in the sense that states find increasing difficulties in exercising their traditional powers. When a society lacks the capacity to take final decisions to promote the human rights of its people, then it can be accepted that responsibility for human rights violations migrates to other agents, including affluent countries that fail to reform international arrangements in order to provide domestic states with the background conditions they need to have real sovereignty. But, however complex the world is becoming, Pogge is too quick to conclude that all instances of human

36. Rawls, The Law of Peoples with The Idea of Public Reason Revisited (Harvard: Harvard University Press, 2000), p 105. The term 'effective sovereignty' is used by Ronzoni (2009), p. 248.

37. Amartya Sen, Development as Freedom (New York, Anchor Books, 1999), chs 7 and 9.

38. See <http://data.worldbank.org/indicator/SI.POV.2DAY> 
rights violations are to be (at least partly) imputed to the failure of the affluent countries to reform the global order. If, as I have argued, some states have the capacity to fulfill the human rights of their citizens but fail to do so, they, not affluent countries, are the relevant violators.

\section{Conclusion}

This article discussed Pogge's thesis that affluent countries are violating the human rights of the global poor. Two alternative interpretations of this thesis were considered. On the first interpretation, this thesis said that affluent countries violate the human rights of the global poor since they sustain an international order, which due to institutional factors, fails to ensure that every person has secure access to the objects of her basic needs. The problem with this interpretation was that the global institutional order had no agency to discharge it. On the second interpretation, Pogge's thesis said that affluent countries violate the human rights of the global poor by upholding an international order that imposes unfair conditions on them, diminishing their capacity to deliver on the human rights of poor people. The problem with this interpretation was that it relied on the false assumption that we bear moral responsibility for all the states of affairs that our acts cause or contribute to causing in violation of a perfect duty. Whether we are to blame for a certain state of affairs we contributed to producing depends on the existing division of the moral labor. In the system of states, states and domestic political communities have perfect duties to promote the human rights of their people even under unfavorable international conditions, at least as long as they keep enough effective sovereignty to do so.

This article concludes that affluent countries are not violating the human rights of the global poor in the ways or for the reasons invoked by Pogge. However, it is not part of my conclusion that the international institutional order is not unfair or that human rights do not require the establishment of new institutional arrangements and new practices. On the contrary, I have argued that the current international order is unfair as long as it imposes asymmetrical rules on its participants. I have also argued that, even within the current system of states, human rights require international practices aimed at ensuring all states the accurate background conditions to promote human rights at home. In this sense, the affluent countries may be violating the human rights of those who live in burdened societies by not providing these societies with the conditions they require to become capable of promoting the human rights of their citizens.

Finally, I hope this article has lent some plausibility to the idea that the definitive eradication of global poverty cannot be achieved by the adoption of any simple measures such as global taxes redirecting money to developing economies or the adoption of new rules for the financial system. In all likelihood, the complete 
eradication of global poverty will require many local measures coupled with important structural modifications of the present global order. Working towards bringing about such a new order is a moral imperative for both affluent countries and affluent people.

Julio Montero

University College London

\section{the global justicenetwork}

